\title{
Chemical Hazards and Allergic Diseases of Furniture Makers and Attitude towards the Use of Protective Equipments in Ethiope East L.G.A of Delta State
}

\author{
Ikogho, Doris Eseoghene ${ }^{1}$, Ikogho, Erasmus Oghenetega ${ }^{2}$ \\ ${ }^{1}$ Department of Health and Safety Education, Faculty of Education, Delta State University, Abraka. Delta State \\ ${ }^{2}$ Department of Applied Physics with Electronics, Federal Polytechnic Nasarawa, Nasarawa State \\ Corresponding Author: IKOGHO, Doris Eseoghene
}

DOI: https://doi.org/10.52403/ijhsr.20220129

\begin{abstract}
The kind of occupation one is involved in is supposed bring happiness, and satisfaction, but it can result in a threat to a worker's health and well-being. The hazard can be in form of chemical such as fire accidents or allergic diseases like conjunctivitis. However, if a worker who is involved in manufacturing processes like the furniture maker has the right attitude and uses personal protective equipment, the hazards will be reduced to the barest minimum.

Objectives: To identify the chemical hazards as well as the allergic diseases to which furniture makers are exposed to. Also, the study seeks to find out the attitude of the furniture makers towards the use of personal protective equipments.

Materials and Methods: the study utilized the descriptive research design. The sample was 300 . This was made up of furniture makers and wood sellers in Ehiope East Local Government Area of Delta State. The study utilized a structured questionnaire to get information from respondents which were the data from the field work. The information so gathered was on chemical hazards and allergic diseases associated with furniture making process as well as on attitude towards the use of personal protective equipments.

Results: Findings from the study indicated that asthma (70\%) and dermatitis (66.3\%) are common allergic diseases. Chemical hazards on the other hand were mostly chapped skin represented by $77.7 \%$, reduced skin temperature $(71.7 \%)$ and fire accidents $(74.7 \%)$. The study also revealed that there is a significant poor attitude of the workmen towards the use of personal protective equipments. Interpretation and Conclusion: the researcher having successfully analyzed the data, concluded from the findings that majority of the furniture makers and wood sellers experienced some forms of chemical hazards and allergic diseases from materials used for processing furniture such as dust from the wood and chemicals for fine finishing. Also, poor attitude towards the use personal protective equipments had contributed immensely to the risks to health. Therefore, the need to design a strategy using engineering control like those found in the study of physics can come handy. This can be relied upon, instead of relying on behavioural change technique. Above all, periodic medical examination for workmen and wood sellers should be encouraged and promoted by the government in all workplaces to mitigate the long term effects of hazards.
\end{abstract}

Key Words: Protective Equipment, furniture, engineering control, Physics

INTRODUCTION

A hazard can also be regarded as a condition which is inherent in any work process. These hazards can be chemical, allergic diseases, physical, biological or even more, are a risk to health and 
wellbeing. He also noted that in many developing countries of the world, not a whole lot is done to lessen such risks of workmen. In developing countries, employers of labour are best inquisitive about profit making to the detriment of the worker ${ }^{1}$. This is reason an employer can hire and fire the worker at any time without any compensation whatsoever ${ }^{2}$. The furniture making enterprise or industry is not exempted from these kinds of hazards. Occasionally, these workmen are provided with Personal Protective Equipment (PPE) such as hand gloves, earplugs, safety glasses, hard hats, coveralls as required by the Personal Protective Equipment at work regulation of 1992. These might also never be used. ${ }^{1}$ Lack of use of PPE is a primary contributing factor for an increase in occupational hazards especially of furniture makers/ wood sellers. ${ }^{3}$ observed that most workmen fail to use personal protective equipment (PPE) primarily based on non secular, non- public notion, religious, personal belief or based on health grounds ${ }^{4}$. The Employment Act of 1989 does not exempt all and sundry from using PPE even on medical grounds. Attitude and personal feelings about PPE can also pose a barrier in increasing hazards. For instance, In a study carried out by Institute of Safety Professionals of Nigeria (ISPON) in 2014, it was confirmed that $34 \%$ of workmen feels that PPE lowers their tempo of work, $20 \%$ says PPE are sometimes uncomfortable, $31 \%$ says PPE are of poor quality and so, obstruct their sight and movement. Only $15 \%$ of the participants agreed that PPE actually save lives. The poor use of PPE is sometimes linked to poor attitude, extreme fitness effects, lack of training, knowledge or management. This situation by implication, promotes illness and absenteeism from work. Poor use of PPE has serious health consequences, massive economic waste and a bad image for any country ${ }^{5}$. A study carried out in Enugu and Owerri wood market in Nigeria by Aguwa, Okeke and Asuzu suggested allergic diseases Asthma and rhinitis and are among the common health problems of wood workers as well as Adenocarcinoma of nasopharynx. The study also indicated that rhinitis is often acute and occur few hours after exposure while Asthma takes about 6 months to 3years to occur following exposure to wood dust. It was in recognition of these risks to health that Occupational and Safety documents recommended certain standard health services, the inspection and monitoring of the work environment as a concern in any work environment. This may be supported by this may be supported by using the country's National Health Insurance Scheme (NHIS) and the Factory Act of $1990^{2}$. Also important is the fact that an effective strategy using engineering control like those found in the study of physics can come handy. They are always built into the design of equipments to reduce injuries. This is so because some of the noticeable hazards of workmen are unavoidable and can only be reduced through engineering. ${ }^{6}$ Hence this technique can actually place a barrier between the hazard and the workman. An example is when exhaust pipe to capture airborne particles or use of machine guards to protect the workman. This method though may be expensive initially, has more advantage health wise One can also isolate and contain the hazards. This method does not require a change in behavior or attitude ${ }^{7}$

It believed that that if a worker truly understands the reason why PPE is needed and at the same time, if PPE are provided for the workman, then such a workman is more likely to wear them to prevent illnesses in different profession. This all important gadget seems to have attracted attention due to its importance in saving lives and reducing consequences of occupational hazards especially chemical hazards and several allergic diseases in the work place. In 2020, the US Centers for Disease Control reported that during the Covid-19, 27 health personnel died due to lack of PPE. The report also suggested that more PPE should be made available for frontline health care staff to protect the 
workers from contracting the infection ${ }^{7}$. Also important is a periodic medical examination to check for signs and symptoms of job related diseases. This is because, every worker needs to undergo frequent radiological or medical checkups to detect early signs of a disease. This method can reduce disabilities, injuries or eventual death of a worker. Statistics in South Africa shows that about $80 \%$ of workers suspect that their illnesses have something to do with the sort of jobs they do so the attitude of the workmen is that lack of use of PPE may not be a major contributing factor for an increase in occupational hazards especially of furniture makers ${ }^{8}$. Hazards of the workplace are classified to include physical hazards, biological hazards, chemical hazards, social hazards, ergonomic hazards and allergic diseases. These hazards are prevalent in every profession and sometimes in the materials used by workmen. Furniture making involves the constant use of wood ${ }^{1}$. Wood is a versatile and most utilized medium in the world, but also inherent in it is its ability to become a potential source of hazard and diseases to those who use them ${ }^{5}$. It was explained that furniture makers turn these woods into a wide range of products such as furniture, sculptures, coffins and more. In so doing several processes are involved which further generate more hazards and put the workman at risks of several injuries or eventual death. Researchers have been able to establish that PPE is an effective protection from hazardous substances at the workplace ${ }^{3}$. In 2015 and 2016 alone, fatalities recorded at the workplace were 144 with 621,000 nonfatal injuries or accidents. It was also recorded that PPE can reduce the risk of bodily injuries in low risk occupation or even in hazardous activities most especially in profession that requires handling fast moving machines and hazardous chemicals such as furniture making $(1,2,5)$.

It was submitted that wood chemicals are corrosive in nature. They can produce dry or "chapped skin and after repeated contact, result in contact dermatitis. According to him, Chlorinated naphthalene may cause primary irritation, which could be acute, capable of reducing skin temperature by rapid vaporisation and also superficial freezing ${ }^{3}$. It was reported that there is an active action against banning imported woods that have been treated with pentachlorophenol and its salts in Canada and United States. These chemicals can penetrate the skin and become the cause of chloracne which is an acute form of acne. It can also bring about liver damage and has been identified as a plausible human carcinogen. If a workman is trained on how to safely store and handled chemical, exposure can be reduced ${ }^{1}$.

It was suggested that the United States looses 65 million dollars annually due to failure to use PPE provided by employers due to little or no training, supervision, poor awareness, misjudgement or human error ${ }^{3}$. It is believed that if workers are trained on the use of PPE or health educated on its importance, then the loss of valuable man hour, absenteeism at work can become a thing of the past. This was why the study seeks to examine the chemical hazards and allergic diseases associated with furniture makers and the use of protective equipments among furniture makers in Ethiope East L. G. A of Delta State.

\section{MATERIALS AND METHODS}

The study provided answers to 2 research questions and one hypothesis. The descriptive survey design was used for the conduct of the study. The population for this study was the entire furniture makers and wood sellers in Ethiope East L.G.A totaling three hundred (300). This was got from the register of the Association of Furniture Makers and Wood sellers Multipurpose Cooperative Society (MPCS) in November, 2021. The sample size was 300 , selected using the systematic sampling technique by picking every odd number from the MPCS register. The questionnaire was constructed to provided answers to 2 research questions and one hypothesis. The questionnaire had a 
reliability coefficient of 0.67 , established by a test-retest method. The questionnaire was validated by 2 experts from the field of Health Education and 1 expert from the field of Physics. Data collected were analyzed using inferential statistics of Chisquare at 0.05 alpha level of significance.

Research Question 1: What are the allergic diseases associated with furniture makers in Ethiope East L.G.A?

Table 1: Allergic diseases associated with furniture makers
\begin{tabular}{|l|l|l|}
\hline Allergic diseases & Yes & No \\
\hline 1. Allergic conjunctivitis (redness of the eyes) & $145(48.3 \%)$ & $155(51.7 \%)$ \\
\hline 2. Acute form of acne & $120(40 \%)$ & $180(60 \%)$ \\
\hline 3. Asthma & $210(70 \%)$ & $90(30 \%)$ \\
\hline 4. Dermatitis due to some dust ( skin problem) & $199(66.3 \%)$ & $101(33.7 \%)$ \\
\hline 5. Upper respiratory tract disease due to allergy to wood dust & $97(32.3 \%)$ & $203(67.7 \%)$ \\
\hline
\end{tabular}

Table 1 shows that $48.3 \%$ of the respondents said yes to allergic conjunctivitis ( redness of the eyes), 51.7\% said no. $40 \%$ said yes to acute form of acne, $70 \%$ said yes to asthma while $30 \%$ said no. Also, $66.3 \%$ said yes to dermatitis due to some dust and no was $33.7 \%$. $32.3 \%$ said yes to upper respiratory tract disease due to allergy to wood dust and no was $67.7 \%$. Therefore asthma and dermatitis are common allergic diseases of furniture makers in Ethiope East L.G. A of Delta State.

Research Question 2: What are the chemical hazards associated with furniture makers?
Table 2: Chemical hazards associated with furniture makers

\begin{tabular}{|l|l|l|}
\hline Chemical Hazards & Yes & No \\
\hline 1. chapped skin & $233(77.7 \%)$ & $67(23.3 \%)$ \\
\hline 2. paralysis & $110(36.7 \%)$ & $190(63.3 \%)$ \\
\hline 3.reduced skin temperature & $215(71.7 \%)$ & $85(28.3 \%)$ \\
\hline 4. fire accidents & $224(74.7 \%)$ & $76(25.3 \%)$ \\
\hline
\end{tabular}

Table 2 shows that the chemical hazards associated with furniture makers are mostly chapped skin represented by $77.7 \%$, reduced skin temperature with $71.7 \%$ and fire accidents represented by $74.7 \%$.

Research Hypothesis 1: Furniture makers in Ethiope East L.G.A will not have significant poor attitude about the use of PPE

Table 3: Hypothesis on attitude about the use of PPE by furniture makers

\begin{tabular}{|c|c|c|c|c|c|}
\hline \multirow[t]{2}{*}{ Responses } & \multicolumn{2}{|c|}{$\begin{array}{l}\text { Good } \\
\text { Attitude }\end{array}$} & \multicolumn{2}{|c|}{$\begin{array}{l}\text { Poor } \\
\text { Attitude }\end{array}$} & \multirow[t]{2}{*}{ Total } \\
\hline & Fo & $\mathrm{Fe}$ & Fo & $\mathrm{Fe}$ & \\
\hline 1. I like to talk about the use of PPE with other workmen & 58 & 128.67 & 242 & 171.33 & 300 \\
\hline $\begin{array}{l}\text { 2. Wearing of PPE will help prevent and reduce the effects of injuries and diseases in the } \\
\text { work place }\end{array}$ & 74 & 128.62 & 226 & 171.33 & 300 \\
\hline 3. I will not like to see a workman injured for refusing to use PPE & 254 & 128.67 & 46 & 171.33 & 300 \\
\hline Total & \multicolumn{2}{|c|}{386} & \multirow{2}{*}{\multicolumn{2}{|c|}{514}} & \\
\hline Mean & 128.67 & & & & \\
\hline Percentages & & & & $\%$ & \\
\hline
\end{tabular}

Critical value is $5.99, d f=2$, significance level $0.05, X^{2}=230.71$

Table 3 shows that $43 \%$ (128) had good attitude about talking about the use of use of PPE with other workmen while 57\% (171) had poor attitude about talking about the use of PPE with other workmen. When subjected to Chi-square statistics, the obtained value $\mathrm{X}^{2} 230.71$ was > than critical value of 5.99 at 0.05 level of significance, the null hypothesis which states that there will be no significant poor attitude in talking about the use of PPE with other workmen was rejected while the alternative was accepted. ${ }^{8}$ This findings correlates with the findings that the attitude of the workmen towards the use of PPE is a major contributing factor for an increase in occupational hazards especially for furniture makers. So getting the right knowledge is important in reducing fatalities. 1 This agrees with the fact that workmen fail to use personal protective equipment (PPE) based on religious, personal belief or based on 
Ikogho, Doris Eseoghene et.al. Chemical hazards and allergic diseases of furniture makers and attitude towards the use of protective equipments in Ethiope East L.G.A Of Delta State.

health grounds. This is because workmen are not aware of the potency of PPE in reducing the rate of injuries, hence the need to create awareness. This an attitudinal problem. This tallies with what was stated that instead of trying to change behaviour, an effective strategy using engineering control like those found in the study of physics $^{6}$.

\section{CONCLUSION}

The data analyzed brought out some useful information as regarding allergic diseases and chemical hazards of furniture makers and attitude towards the use of PPE to reduce injuries and illnesses. The study revealed that most workmen and wood sellers have poor attitude towards the use of PPE. There were allergic diseases and chemical hazards associated with the work process in furniture making that can be prevented through engineering.

\section{Recommendations}

Therefore, the need to design a strategy using engineering control like those found in the study of physics can come handy. This can be relied upon, instead of relying on behavioural change technique. Above all, periodic medical examination for workmen and wood sellers should be encouraged and promoted by the government in all workplaces to mitigate the long term effects of hazards. The government of Delta State can help set up Health and Safety department to monitor the work environment to increases safety consciousness among others.
Conflict of Interest: None

Source of Funding: None

Ethical Approval: Approved

\section{REFERENCES}

1. Achalu, E.1. Occupational Health and Safety 2014. Lagos: Splendid Publishers.

2. Nwachukwu, A.E (2000). Industrial Health and Safety. Owerri. Totan Publishers.

3. Omobude- Idiado, S.N., Irimonre, E. L \& OhiAsikhia, M (2013). Occupational Health hazards in Sawmill Industries in Benin City. Nigerian School Health Journal, 9(25)1-9.

4. Lucas, A. O. \& Gilles, H. M. (2003). Short textbook of public health medicine for tropics. London: Arnold Publishers

5. Ikogho D.E., \& Olikiabor S.I. (2018). Health and Wellness in Ikponmwosa Owie (Ed.) Place of Safety in Wellness(pp 278295).Benin City Edo State:Ambik Press

6. Wikipedia. Granpa, (2020). Physical Hazards Retrieved from en.m.wikipedia.org

7. GlobalData, (2020). Fragile State Index. Washington, D C. 20009. United States of America. Available at https://fragilestatesindex.org/data/

8. Ikogho, D. E. (2009). Hazards Associated with Furniture Makers in Ughelli North L.G.A of Delta State. Unpublished Master's Thesis.

How to cite this article: Ikogho, Doris Eseoghene, Ikogho, Erasmus Oghenetega. Chemical hazards and allergic diseases of furniture makers and attitude towards the use of protective equipments in Ethiope East L.G.A Of Delta State. Int J Health Sci Res. 2022; 12(1): 218-222. DOI: https://doi.org/10.52403/ijhsr. 20220129

Acknowledgement: None 